\title{
The Impact of Zero Tolerance Policy on Children with Disabilities
}

\author{
Mariam Alnaim ${ }^{1, *}$ \\ ${ }^{1}$ Saint Louis University, USA \\ *Correspondence: Saint Louis University, USA. E-mail: mjn_srror@hotmail.com \\ Received: December 31, $2017 \quad$ Accepted: January 17, 2018 Online Published: January 29, 2018 \\ doi:10.5430/wje.v8n1p1 \\ URL: https://doi.org/10.5430/wje.v8n1p1
}

\begin{abstract}
The Zero Tolerance policy was intended to eliminate learners who are a danger to a learning institution (Henson, 2012). The development of this policy was to assist schools with better policing approaches of students conducts by employing tough disciplinary action and subsequently provide a safer learning environment. While the Zero Tolerance policy sought to reinforce security measures in schools, the students with emotional or learning disabilities and behavioral disorders were predisposed to expulsions and suspensions (Henson, 2012). The situation is facilitated by the all-encompassing nature of this policy as it fails to accommodate the fact that some of the behaviors demonstrated by students with disabilities are beyond their control. While some of these behaviors are considered to fall under the zero-tolerance policy guidelines, it subjects this group of learners several disciplinary actions that were not initially included in addressing their special needs.
\end{abstract}

Keywords: Zero Tolerance policy, children with disabilities, education safety

\section{Introduction}

Safety in educational institutions has increasingly become a state concern in the wake of school shooting cases (Sheras \& Bradshaw, 2016). The 2008's National Center for Education Statistics report indicates that during the 2006 to 2007 academic period, nearly half of all public learning institutions had a minimum of one serious academic disciplinary case. They involved the use or possession of a weapon, alcohol or drug possession, and physical assault (Henson, 2012). The total reported disciplinary cases were 800,000 with 5 percent of them being expelled and 74 percent getting a five-day or more suspension (Henson, 2012). School shootings have resulted in death and injuries of both students and faculty members.

The Zero Tolerance policy was intended to eliminate learners who are a danger to a learning institution (Henson, 2012). The policymakers are responding to the outcry from the public regarding better safety measures at the school campuses while also dealing with situations and people with dissimilar severity degrees (Sheras \& Bradshaw, 2016). The development of this policy was to assist schools with better policing approaches of students conducts by employing tough disciplinary action and subsequently provide a safer learning environment.

While the Zero Tolerance policy sought to reinforce security measures in schools, the students with emotional or learning disabilities and behavioral disorders were predisposed to expulsions and suspensions (Henson, 2012). The situation is facilitated by the all-encompassing nature of this policy as it fails to accommodate the fact that some of the behaviors demonstrated by students with disabilities are beyond their control. While some of these behaviors are considered to fall under the zero-tolerance policy guidelines, it subjects this group of learners several disciplinary actions that were not initially included in addressing their special needs.

Previous studies have indicated that special education learners have increased tendencies of disruptive behaviors that immediately qualify them for the disciplinary actions proposed (Henson, 2012). Special education learners are frequently involved in classroom disruptions, violation of the dress code and other small contraventions that administrated handled previously. Employing the disciplinary zero tolerance policy while ensuring that the students get maximum punishment proposed the circumstances notwithstanding is both detrimental to the stigmatized or labeled group and presents a significant burden to the educational system.

Special education students have challenging behaviors, and the expectations of the administrators and educators 
regarding this group are quite low. As such, educators and administrators are more likely to use the zero-tolerance policy when handling the learners when classroom management practices are inefficient (Henson, 2012). As such, most of the special education learners are overrepresented in the reported expulsion and suspension cases. Examining the relationship between prevalence of students with learning and emotional disabilities and the frequency of their expulsions and suspensions in schools employing the Zero Tolerance policy underscores the stigmatization of this group.

\subsection{Safety Measures in Schools}

Policymakers, parents, and educators have been concerned about ensuring a conducive and safe working environment all through the years. However, schools have continued to record increasing violence rates across the United States. For instance, about 31 percent of the students between Grade 9 and 12 were involved in a minimum of a physical fight with 11 percent of them while at the learning institution (Losinski, Katsiyannis, Ryan, \& Baughan, 2014). Further studies indicate seventeen percent of teens had a weapon, with 6 percent while in school, 21 percent used marijuana with five percent while in school and 42 percent had consumed alcohol with four percent while at school (Losinski et al., 2014). The disciplinary action taken within the 2007-2008 academic year included five percent getting expelled without services for the rest of the year, 19 percent transferred to specialized schools while 76 percent were suspended for five or more days (Losinski et al., 2014).

There are disturbing disparities regarding the disciplinary infractions among special education learners and those from ethnically diverse students. Studies highlighted that special education and minority students had higher chances of getting expelled from school due to disciplinary actions (Losinski et al., 2014). The reports also underscored the association between removing a learner from school on disciplinary grounds and the risk of being contacted by the juvenile justice system, dropping out or repeating a grade.

The aftermath entailed school districts establishing and implementing several safety measures, but the evidence is inconclusive regarding how they affect the frequency of violence in school (Losinski et al., 2014). Between 1999 and 2008, learning institutions have enhanced the provision of telephones in classrooms to seventy percent from forty-five percent and the utilization of security cameras to fifty percent from twenty percent (Losinski et al., 2014). They also increased the utilization of picture IDs and badges by students to eight percent from four percent and faculty members to sixty percent from twenty-five percent, controlled access to school buildings from ninety percent from seventy-five percent and school grounds from forty percent from thirty percent (Losinski et al., 2014).

Moreover, schools have collaborated with researchers to create behavior management plans such as the school-wide positive behavioral supports and interventions. Even with the significant steps taken by the school district to minimize shootings in schools with troubling events happening in Chardon, Ohio that received extensive media coverage (Losinski et al., 2014). Naturally, school officials felt the pressure to take employ additional mechanisms including taking draconian steps to guarantee students utmost safety while on school grounds (Sheras \& Bradshaw, 2016). However, reactionary events led to unplanned implications that prove to be harmful to many learners. In the recent years, schools have largely adopted the Zero tolerance policies that have a compulsory punishment for learners the nature of the offense, the student's record or circumstances notwithstanding.

\section{Legislation}

Learning institutions adopted the zero-tolerance policy under the government Gun-Free Schools Act (GFSA) that mandated learners to be expelled from school for one year whenever they bring firearms (Losinski et al., 2014). Institutions that fail to observe the provisions in the Act risks losing the funds as required by the Elementary and Secondary Education Act (Losinski et al., 2014). While the federal government introduced the Zero Tolerance Act, the interpretation varied among states with some stretching the policies to include firearms and weapons, fights, alcohol and drugs, dress code violation, disrespect, insubordination, truancy and swearing (DeMitchell \& Hambacher, 2016).

The conception of the zero-tolerance policy was to impose similar harsh consequences on all learners, thus; minimizing disparities (Sheras \& Bradshaw, 2016; DeMitchell \& Hambacher, 2016). However, the aftermath highlighted race, economic, and disability disparity increasing rapidly from the mid-1990 when the zero-tolerance policies were introduced (Biehl et al., 2012). The harsh discipline practices have disproportionally harmed vulnerable children including the minority, the economically disadvantaged, and those with a disability. A study done in Ohio in the 2010-2011 academic years indicated that learners with emotional disorders had 7.2 times increased the possibility of getting a suspension when compared to those without any disability (Biehl et al., 2012). Moreover, the learners 
with cognitive incapacities had 2.5 times increased chances of getting a suspension than those without any disability (Biehl et al., 2012).

Zero tolerance policies have no regard for the underlying sources of the learners' actions. Some of these behaviors are because of many factors including the children not being taught appropriate behavior, poverty, trauma, safety concerns at home, hunger, and disability (Biehl et al., 2012). Administrators and educators are only keen on expelling or suspending learners from school without even discerning the underlying problems and determining the appropriate measures that would help students learn positive responses amidst the challenges.

It is important to underscore that removing any learner from school is quite problematic and devastating to them and particularly those students with disabilities. It makes it difficult for them to catch up which, be frustrating, and subsequently increase the dropout cases. In the 2010-2011 academic years, the total number of students with disabilities enrolled in public schools represented fifteen percent, but twenty-seven percent of them were suspended within the same year (Biehl et al., 2012). The zero-tolerance policies are inflexible and have prevented school districts from offering a more professional judgment. The aspects to be considered include the learner's history of offenses, circumstances, the seriousness of the offense, special education status, age, gender, the impact of the offense and the resiliency level of the learner when establishing the efficient and appropriate disciplinary action (Biehl et al., 2012).

The disparities are significantly high and raise major concerns about equality and fair treatment. The Individuals with Disabilities Education Act stipulates that learning institutions should deliver individualized education programs (IEPs) to special education learners, perform evaluations on their functional conduct, and incorporate positive behavioral interventions and supports (PBIS) (Lipkin \& Okamoto, 2015). When schools use the zero-tolerance policies to discipline cases of disrespect, noncompliance, and defiance among the special education learners, it contravenes with the IDEA (Lipkin \& Okamoto, 2015). Special education laws promote an intricate and highly personalized inquiry before subjecting any student with a disability to significant discipline involving suspension for more than ten days or expulsion (Sullivan, Van Norman, \& Klingbeil, 2014). Educators are supposed to use the IEPs to establish appropriate behavior goals and use the appropriate tools to address behavioral issues and not just suspending the special education students whenever they cat out.

IDEA provides that whenever a school district seeks to suspend for more than ten days or expel a special education student, the standard question that must be answered is if the behavioral issue was a manifestation of the disability of the learner (Lipkin \& Okamoto, 2015). For one to determine if the misconduct was not associated with the learner's disability manifestation, the following pointers must be considered. First, the IEP and placement should be appropriate, and the school should be offering services, which are consistent with their needs (Sullivan, Van Norman, \& Klingbeil, 2014). Sometimes, their disability should not affect their ability to regulate their actions.

The school district may not discipline the learner if any of these conditions are not met. In such events, it is the IEP team's responsibility to determine strategies for averting such actions in future. If the conclusion provides that the behavior not in any way as a result of the child's disability manifesting, the school district may impose and any discipline proposed for any student. However, it must also keep providing educational services to the special education learner even when the action warrants an expulsion (Sullivan, Van Norman, \& Klingbeil, 2014). Most administrators are uninformed or ignorant of the intricate procedures needed when disciplining special education learners. Usually, officials in schools stipulate that the application of the zero-tolerance policies must be across the board, the nature of the student notwithstanding (DeMitchell \& Hambacher, 2016). Nevertheless, the special education laws override the state or federal law including the zero-tolerance policy.

\section{Litigation}

The determination of the nature and prevalence of the zero-tolerance policies looking at some of the cases reported in the previous years involving the use of zero tolerance policies to offer disciplinary actions to different types of students.

\subsection{General Education Case Law}

Over the years, several cases have been determined by courts regarding general education students involved in misconducts like possessing weapons, drugs and alcohol, and defiance and received discipline under zero-tolerance policies. Some of the cases include the State of New Mexico v. Rowell, 2008 where an officer stopped a speeding car in the school zone and noticed a bag of Marijuana openly exposed. The defendant told the officer about a weapon being in the car (Losinski et al., 2014). The ruling indicated that since no weapons were allowed in school, the 
officer was justified to search the car. In the J. M., v. The Webster County Board of Education, 2000 case, a learner was expelled for twelve months by the School District for having a firearm while in school (Losinski et al., 2014). During the determination, the court held that it was illegal for the students to have a weapon while in school and therefore upheld the expulsion. Another example is J.P.M. v, Greenbrier County Board of Education, 1996 where the school district expelled the learner for two semesters for carrying a gun while in school (Losinski et al., 2014). The court maintained that while the leaner has forfeited his right to attending school, his right to education was to be reconsidered.

In the Seal v. Morgan, 2000 case, the school district expelled a high school student after a knife belonging to a friend was discovered in his car's glove compartment (Losinski et al., 2014). The plaintiff denied being aware of that the knife was in the car and contended that the school board had violated his right. The ruling indicated that the school board might not clear itself of its responsibility to establish if learners deliberately committed acts, which warranted expulsion. The C.E.A v, Doddridge County Board of Education, 1997, a student was found with knives in school on two occasions (Losinski et al., 2014). The student was expelled from school for years and asked the parent to pay the teacher fee to facilitate homeschooling. While the court agreed to the decision during the ruling, it objected the idea of the parent paying the fee.

In the Jane Doe v. Schools of Worcester, 1995 case, a learner with a suicide history was expelled from school for twelve months for coming to school with a knife in a lipstick case. The school upheld the decision (Losinski et al., 2014). Hinds County School District Board of Trustees v. R.B, 2008 involved the district expelling a learner for having drugs as well as a knife that was considered a nail file by the student. The school board asked the superintendent to determine what should be considered a weapon in this regard (Losinski et al., 2014). In the State of Wisconsin v. Angela D. B., 1997 case, the administrator received information that a student had a knife. The principal asked the liaison information officer to search the student, and a knife was found in her waistband. The court maintained that the search was rational as a precaution to maintain the safety of the faculty members and students

\subsection{Special Education Case Law}

Several cases involving special education students for drugs, weapon-related or other cases have been handled. The students may possess different weapons including scissors, knives, and guns and pose a threat to other students and faculty members. For instance, there has been a student in his $6^{\text {th }}$ grade and diagnosed with ADHD, learning disability, and Asperger's syndrome pulling the tie of the school administrator (Losinski et al., 2014). Another case includes a grade 8 learner being expelled from being expelled from school for possessing a knife while in school and giving it to his peers. In Doe v. Todd County School District, 2010, a learner with a reading disability was suspended having a knife and fighting while in school. The learner was placed on IES for 38 days by the IEP team (Losinski et al., 2014).

At Madison City Board of Education, a learner with SLD was put on homebound status after bringing a gun in school. An appropriate IEP was developed then implemented by the school district, and it revealed that the violation of the Gun-Free School Act and school code regarding weapons was not because of his disability manifestation (Losinski et al., 2014). In Chester Upland School District, a sixteen-year-old learner was put in an IAES for having a retractable blade and cigarette lighter while in school. An initial healing had regarded the cigarette lighter as a non-weapon (Losinski et al., 2014). The state reviewed the case and overturned as lighter falls under weapons.

The Colvin by Colvin v. Lowndes County School District, 2000 involved the school district expelled a twelve-year student with ADHD/ ADD doe carrying a Swiss-army knife. Once the student was asked about being in possession of a knife, she agreed and presented it to the teacher (Losinski et al., 2014). The parent sued the school district, and it was determined that it violated the rights of the student and IDEA by expelling him. The parents asked the district to assess her son's disability status and not simply to treat him as a learner without any disability.

\section{Conclusion and Recommendations}

It is the responsibility of learning institutions to maintain the integrity and safety of the environment to allow for better learning experiences. The school instills in the learners interpersonal and personal skills that will help them fit into and be successful in the society and school. It also encourages a productive and positive learning environment, preserves a safe climate and minimizes the possibilities of any disruptions in future. Several studies have highlighted the insufficiencies of this policy and its failures as the standard system for effective discipline in schools.

While the significance of the students' and faculty members' safety while in school is mostly highlighted, administrators and educators also have the responsibility of handling the cases on an individual basis and not 
imposing a consistent disciplinary action, the circumstances notwithstanding. The zero-tolerance policy focuses on removing the disruptive students from the school. However, the cause of disagreement arises regarding whether suspension and expulsion as disciplinary actions benefit the punished student in any way or it only creates a safer and better learning environment for the remaining students.

Furthermore, while initially the zero-tolerance policy was only meant for weapon control, currently states have included other offenses that they consider should be punishable by these policies. The inclusion of all other destructive behavior on the ever-expanding list does not guarantee the well-being and safety of the faculty members and students. Furthermore, it does not improve the student's behavior, and most of the studies have considered it counter-effective.

Lastly, the disparities recorded in the previous reports reinforces the fact that these roles should be re-evaluated and streamlined to serve their primary purpose of enhancing security in learning institutions. Students with disabilities have to deal with numerous issues while in school including stigma, highly stressful life situations, and abuse and imposing on them such harsh disciplinary actions exacerbates their situation. The effects of overusing the zero-tolerance policies to discipline the students are dire and profoundly negative. School districts should, therefore, not only start handling disciplinary bases on a one-on-one basis but also develop more sensible and flexible policies that encompass all the confounding factors that should be put into consideration when dealing with students with disabilities.

\section{References}

Biehl et al. (2012). Zero Tolerance and exclusionary School Discipline Policies Harm Students and Contribute to the Cradle of Prison Pipeline. Ohio Department of Education. Retrieved from http://www.cdfohio.org/assets/pdf-files/issue-brief-zero-tolerance.pdf

DeMitchell, T. A., \& Hambacher, E. (2016). Zero tolerance, threats of harm, and the imaginary gun: Good intentions run amuck. $B Y U E d u c . \& L J, 1$.

Henson, M. (2012). Issues of Crime and School Safety: Zero Tolerance Policies and Children With Disabilities. Electronic Theses and Dissertations. Paper 2454.

Lipkin, P. H., \& Okamoto, J. (2015). The Individuals with Disabilities Education Act (IDEA) for children with special educational needs. Pediatrics, 136(6), e1650-e1662. https://doi.org/10.1542/peds.2015-3409

Losinski, M., Katsiyannis, A., Ryan, J., \& Baughan, C. (2014). Weapons in schools and zero-tolerance policies. NASSP Bulletin, 98(2), 126-141. https://doi.org/10.1177/0192636514528747

Sheras, P. L., \& Bradshaw, C. P. (2016). Fostering Policies That Enhance Positive School Environment. Theory into Practice, 55(2), 129-135.

Sullivan, A. L., Van Norman, E. R., \& Klingbeil, D. A. (2014). The exclusionary discipline of students with disabilities: Student and school characteristics predicting suspension. Remedial and Special Education, 35(4), 199-210. https://doi.org/10.1177/0741932513519825 